\title{
Tunnel lighting design: 3D modeling reduces whole of life cost
}

\author{
R. A. Morrison \\ AECOM Pty Ltd, Industry Group, Australia
}

\begin{abstract}
Increasing populations in cities means more money, energy and time is spent on the transport of people. Finding more energy efficient methods in designing and constructing transport infrastructure is essential to the sustainable future of urban living. This case history paper explains the methods adopted and results achieved by designing the tunnel lighting system for a typical transport tunnel in Australia with detailed 3D modelling software in a departure from usual methods.

Transport tunnel lighting systems are usually studied in software models that assume the tunnel is a symmetrical flat floored and straight sided tube structure. In most cases transport tunnels are never flat floored, symmetrical or straight sided. Using a 3D CAD model of the tunnel interior in lighting software capable of calculating complex spaces a realistic lighting model can be created. This model is used to comparatively analyse the various lighting products available to find the best for purpose solution to the design. Whole of life cost analysis is used to understand which lighting system will provide the lowest overall operating and maintenance cost.

Calculating the lighting in a 3D model also predicts installed compliance. The results of a post installation audit of the lighting shows a high level of delivered accuracy. This translates to a safer driving environment, reduced overall installation costs, lower whole of life energy consumption, maintenance costs and reduced carbon emissions when compared to more traditional design methods.

Keywords: tunnel lighting design, 3D modeling, whole of life cost analysis.
\end{abstract}




\section{Introduction}

Transport tunnels are increasingly used in cities to solve above ground traffic problems. Brisbane City in Queensland Australia is no different. As part of a dedicated Bus way traffic system throughout the metropolitan area of Brisbane, the Eastern Bus way Alliance designed and constructed two bus tunnels in 2009. The project was completed in June 2011. These tunnels, called Logan and Laura are the subject of this paper, a case study of the modelling used to design the lighting and a whole of life cost analysis.

\section{Tunnel lighting design parameters}

The key metrics for designing tunnel lighting are described in detail in the standards called CIE: 88 (2004) and AS1158.5 (2007). The interplay of reflection of light inside tunnels is a vital element in delivering a successful design. The tunnels were designed to the requirements detailed in AS1158.5 (2007).

Table 1: Calculation of L20 and Lth - Logan western portal.

\begin{tabular}{|c|c|c|c|}
\hline ELEMENT & AREA & $\begin{array}{l}\text { LUMINANCE FROM } \\
\text { TABLE H1 / H2 - FOR } \\
\text { FACING N/NEAST }\end{array}$ & $\begin{array}{c}\text { LUMINANCE OF THE } \\
\text { AREA } \\
\text { candelas }\end{array}$ \\
\hline $\begin{array}{l}\text { ITEM } 1 \\
\text { SKY }\end{array}$ & 51.9475 & 15000 & 779212.50 \\
\hline $\begin{array}{l}\text { ITEM } 4 \\
\text { FENCE }\end{array}$ & 32.1440 & 4000 & 128576 \\
\hline $\begin{array}{c}\text { ITEM } 2 \\
\text { ENTRY PORTAL } \\
\text { (R1 SUFACE) }\end{array}$ & 61.4326 & $\begin{array}{c}(1 / 4 \text { OF } 8000 \times 1.5) \\
2000\end{array}$ & 122865.2 \\
\hline $\begin{array}{c}\text { ITEM } 5 \& 6 \\
\text { CONCRETE SIDE- } \\
\text { WINGS }\end{array}$ & 70.7689 & 6000 & 424613.4 \\
\hline $\begin{array}{c}\text { ITEM } 3 \\
\text { ROAD (R1) }\end{array}$ & 131.2187 & 8000 & 1049749.6 \\
\hline $\begin{array}{c}\mathbf{L 2 0}=\mathrm{L} / \mathrm{A} \\
=7150.44 \mathrm{~cd} / \mathrm{sqm}\end{array}$ & $\begin{array}{c}\text { TOTAL AREA } 350.33 \\
\text { SQM }\end{array}$ & & $\begin{array}{c}(\mathbf{L}) \\
\text { TOTAL LUMINANCE } \\
2,505,016.7\end{array}$ \\
\hline $\begin{array}{c}\mathbf{k}=0.05 \\
(\text { TABLE 3.1, As1158.5) }\end{array}$ & & & $\begin{aligned} & \text { Lth } \\
= & \mathrm{k} \times \mathrm{L} 20 \\
= & \mathbf{3 5 7 . 5}\end{aligned}$ \\
\hline
\end{tabular}




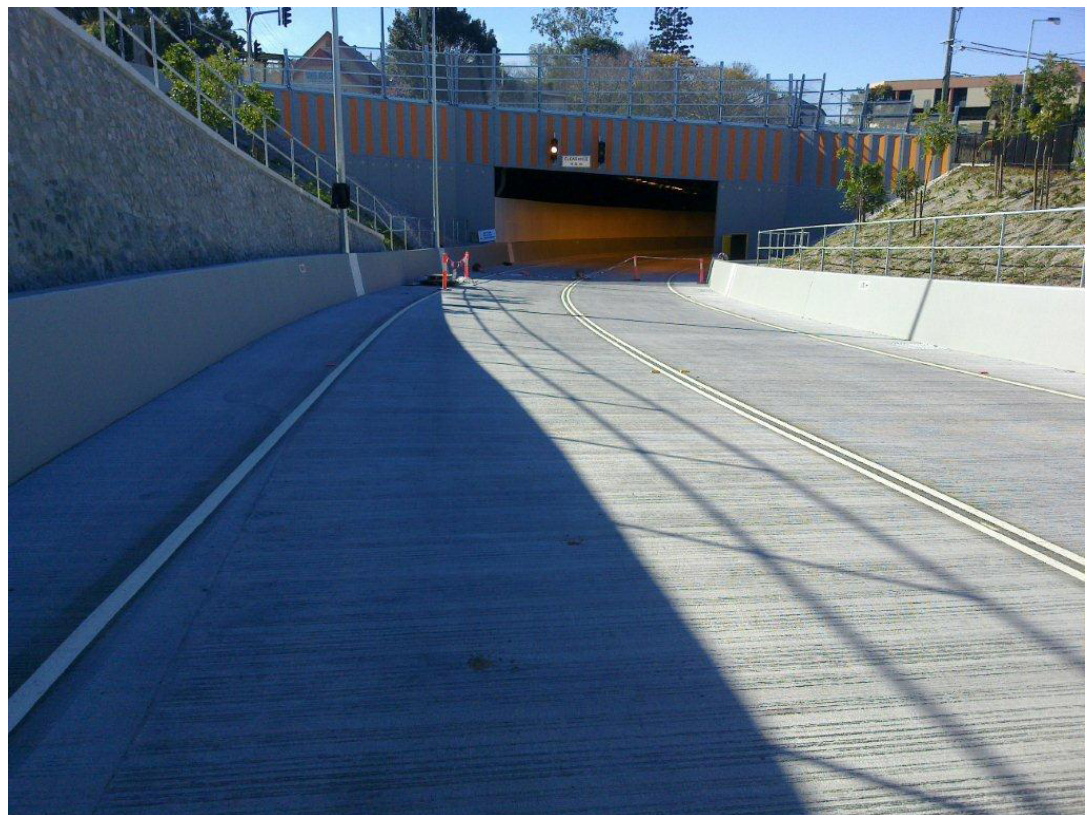

Figure 1: $\quad$ Photo of the as built western portal.

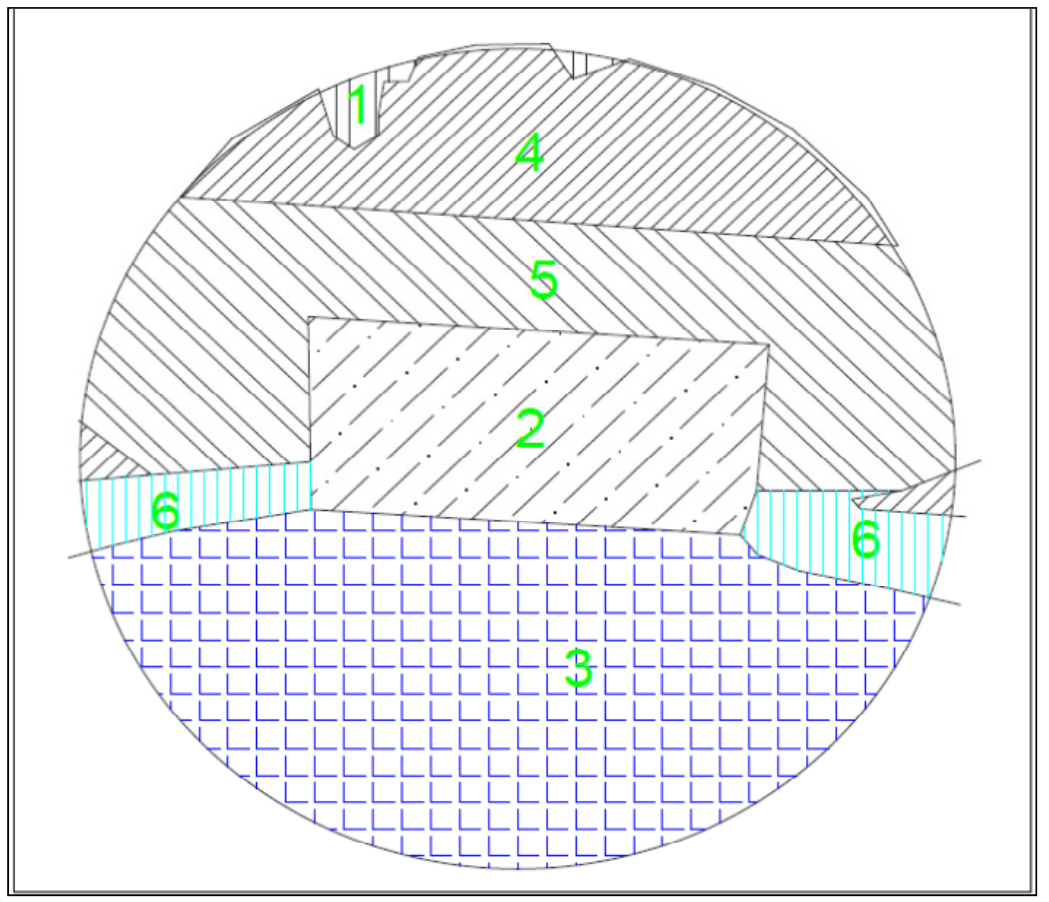

Figure 2: $\quad$ AutoCAD map of the portal elements. 
The design parameters of the Logan tunnel lighting system are follows:

Road surface CIE R1 (Concrete);

Wall reflectance 0.60 ;

Concrete barrier reflectance 0.35 ;

Ceiling reflectance 0.15 ;

Maintenance factor Fluorescent: 0.64; HPS: 0.60;

Luminaire optical mounting height 5.025 meters;

Tunnel width: - Varies - 10.5 to 12 meters;

Design maximum speed: Laura and Logan Tunnel $50 \mathrm{~km} / \mathrm{h}$;

Safe stopping distance 60 meters (at $50 \mathrm{~km} / \mathrm{h}$ ).

\section{Choice of luminaires}

The choice of light source is primarily driven by the factors of lifespan and efficacy. High pressure sodium (HPS) light sources offer the most durable, long life options with the highest light output.

Choosing light sources for the night time and emergency switch modes is also a practical decision. With the need for the emergency lighting to be instantly switched on, fluorescent or LED sources are preferable. The night lighting system while static for a long period of time can be provided with either HPS, fluorescent or LED sources. Fluorescent and HPS light sources are capable of withstanding the high temperatures. In the tunnels it was decided to use fluorescent for both the emergency and night lighting switches.

Of the five companies were invited to offer tunnel lighting products three responded with acceptable offerings. Each of these suppliers products, (Suppliers A, B and C) was tested in a model of the tunnel to ascertain the most efficient and practical supplier.

\section{Creating a simple model}

Transport tunnels are rarely symmetrical or straight sided rectangular forms. They often have curving floors, walls and complex ceiling structures above. In spite of this, many models for lighting design use a simple rectangular extrusion form based on the cross section of the portal opening. This sort of model was created for the Logan tunnel using the western portal cross section and the same design parameters. The essential difference between this model and the more complicated 3D model is the limited dimensional parameters. The simple model assumes that the walls are parallel and the floor flat. In the actual design layout of Logan tunnel the walls floor and ceiling are curved. Part of the calculation process available to the designer using such a model is factoring. Normal factoring in lighting is as agreed with the IES/CIE, and involves the maintenance of fitting and equipment, the natural decline in output of lamps and the steady decline in surface reflectance. The simple versions of software programs used to create basic rectangular models have a further allowance, called the design factor (Rayforge Services [1]). This is a factor, or an allowance, and allows for all sorts of poorly defined elements in the design process. 
Table 2: $\quad$ Calculation results summary - average luminance 225.89.

\section{Calculation Summary}

Label CalcType Units Avg Max Min Min/Avg Min/Max Max/Avg RTable ActQVal

\begin{tabular}{lll|l|l|lllll} 
Road_Illum Illuminance & Lux & 3140 & 4255 & 1528 & 0.49 & 0.36 & 1.35 & N.A. & N.A.
\end{tabular}

$\begin{array}{lllllllll}\text { Road_Luminance_Luminance } & \text { Cd/Sq.m } & 204.22 & 306 & 106 & 0.52 & 0.35 & 1.5 \text { NZN4 } & 0.09\end{array}$

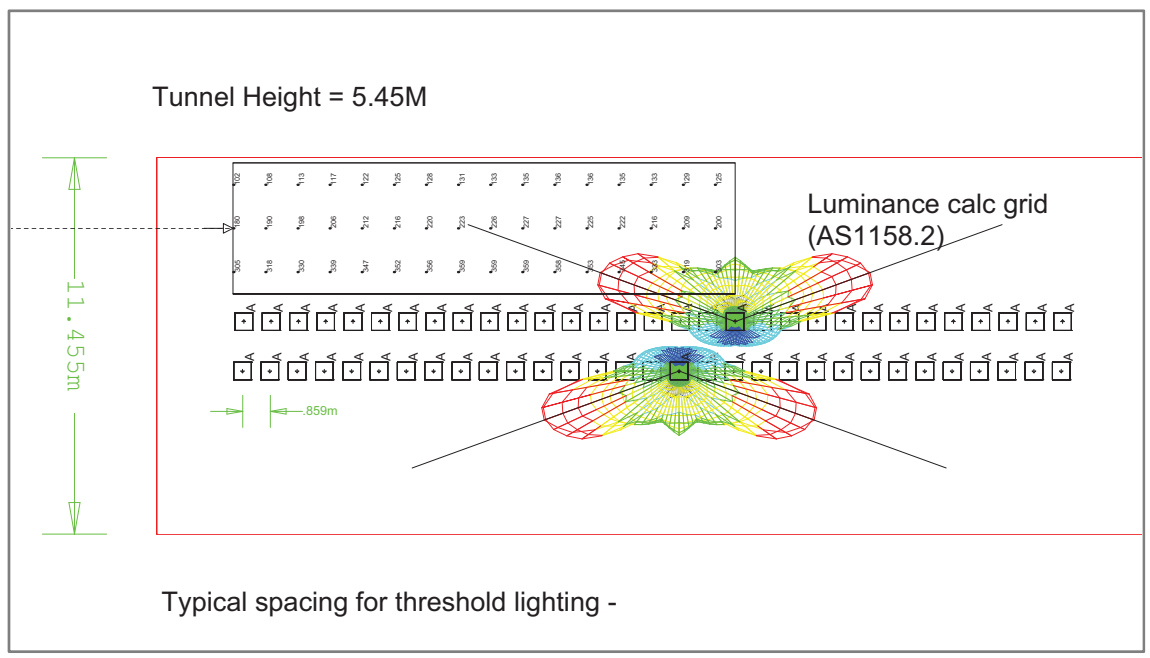

Figure 3: $\quad$ Example lighting layout of simple model plan view - supplier A.

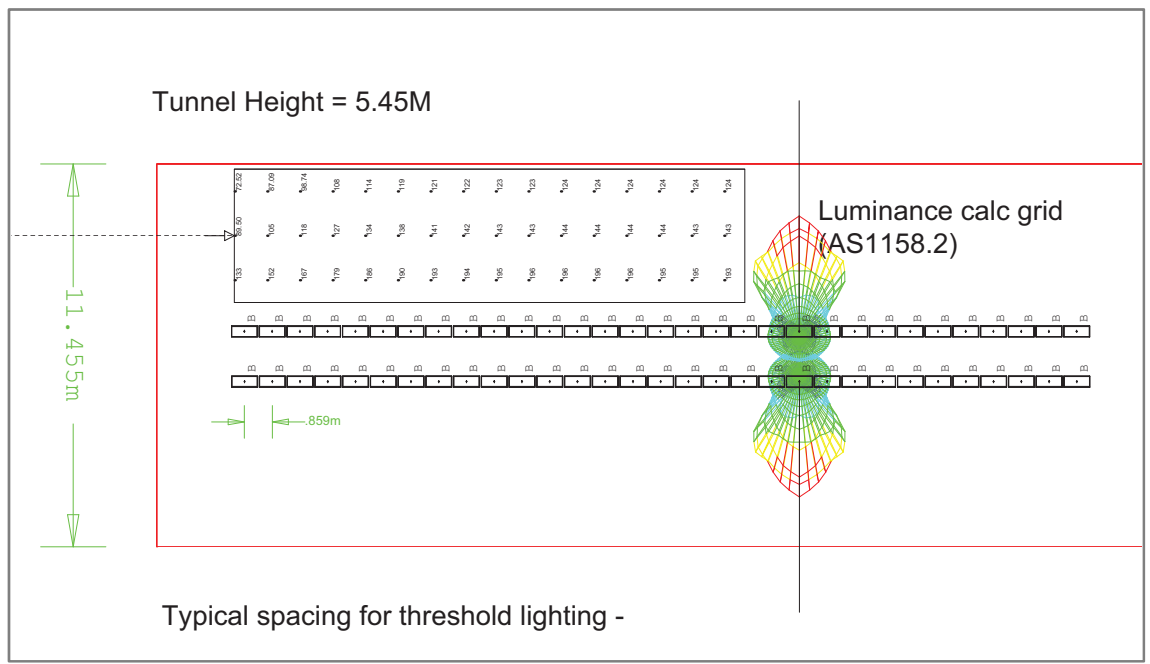

Figure 4: $\quad$ Example lighting layout of simple model plan view - supplier B. 
Each suppliers light fittings were tested in the simple model. Several iterations provided the answer to the technical requirements, and luminaire type A proved to be the more efficient option, providing more luminance to the carriageway per light fitting per linear meter of tunnel than the other choices. Results of this are in the following examples.

Table 3: Calculation results summary - average luminance 188.44.

\begin{tabular}{|l|l|r|r|r|r|r|r|r|r|}
\hline \multicolumn{2}{l}{ Calculation Summary } & & & & & & & \\
\hline Label & CalcType Units & Avg & Max & \multicolumn{1}{l|}{ Min } & Min/Avg & Min/Max & Max/Avg RTable ActQVal \\
\hline Road_Illum & Illuminanc Lux & 2829 & 4562 & 1103 & 0.39 & 0.24 & 1.61 N.A. & N.A. \\
\hline Road_Luminance_Luminanc Cd/Sq.r & 188.44 & 326 & 70.36 & 0.37 & 0.22 & 1.73 NZN4 & 0.09 \\
\hline
\end{tabular}

\section{Creating a more realistic straight model}

Having created and tested a simplified model, a more complicated model can be developed using the real dimensional relationship of wall to carriageway. Consideration has to be given to some key realities. Firstly, should the lighting model utilize a curved carriageway? If the lighting system in the tunnel is installed parallel with the carriageway, then the carriageway curve is irrelevant to the model. The wall linings are also set at a standard height above the carriageway. So effectively the lighting system and wall linings arrangement are in a static relationship with the carriageway, so there is no point in producing a curved floor model. The horizontal relationship of all the elements is the key to producing an effective 3D model. There are many instances where the carriageway widens, the barriers change dimension, and the roof system rises up or lowers down. Co-contributions from the walls is a significant factor in lighting for tunnels, so accuracy in assessing the relationship of the lighting system to the key reflecting surfaces is important in terms of both performance, and sustainable use of resources. Using the CAD information available, a lighting modelling program can be used to create the correct shape of the tunnel form as a virtual shell (Lighting Analysts [2], Dialux [3]). Still with straight sides, the side dimension is scaled to the longer of the curved sides, effectively lengthening the model. In this structure the lighting is tested once again for accuracy and adjustments made to ensure light technical parameters are met. The greatest dilemma in all this is the fact that the road luminance calculation system is based upon a straight sided calculation grid with an observer eye position exactly in

Table 4: $\quad$ Calculation results summary for Logan west portal.

\begin{tabular}{|c|c|c|c|c|c|c|c|c|c|c|}
\hline \multirow{2}{*}{$\begin{array}{c}\text { Calculation Summary } \\
\text { Label }\end{array}$} & \multirow[b]{2}{*}{ Calc Type } & \multirow[b]{2}{*}{ Units } & \multirow[b]{2}{*}{ Avg } & \multirow[b]{2}{*}{ Max } & \multirow[b]{2}{*}{ Min } & & & & & \multirow{3}{*}{$\begin{array}{c}\text { ActQVal } \\
0.1\end{array}$} \\
\hline & & & & & & \multicolumn{4}{|c|}{ Min/AvgMin/MaxMax/Avg RTable } & \\
\hline west portal_1_L & Long. Uniformit & $\mathrm{Cd} / \mathrm{Sq} . \mathrm{m}$ & 363.5 & 405 & 265 & 0.73 & 0.65 & 1.11 & R1 & \\
\hline west portal_1_L & Luminance & $\mathrm{Cd} / \mathrm{Sq} . \mathrm{m}$ & 328.97 & 405 & 210 & 0.64 & 0.52 & 1.23 & $\mathrm{R} 1$ & 0.1 \\
\hline west portal_2_L & Long. Uniformit & $\mathrm{Cd} / \mathrm{Sq} . \mathrm{m}$ & 298.25 & 333 & 262 & 0.88 & 0.79 & 1.12 & R1 & 0.1 \\
\hline west portal_2_L & Luminance & $\mathrm{Cd} / \mathrm{Sq} . \mathrm{m}$ & 273.67 & 333 & 225 & 0.82 & 0.68 & 1.22 & $\mathrm{R} 1$ & 0.1 \\
\hline lth3_Long_Unif & Long. Uniformity & $\mathrm{Cd} / \mathrm{Sq} . \mathrm{m}$ & 90.33 & 121 & 61 & 0.68 & 0.5 & 1.34 & R1 & 0.1 \\
\hline lth3 Luminance & Luminance & $\mathrm{Cd} / \mathrm{Sq} . \mathrm{m}$ & 86.33 & 127 & 53 & 0.61 & 0.42 & 1.47 & R1 & 0.1 \\
\hline
\end{tabular}


from of the calculation grid. This of course will never suit the calculation of a curved tunnel, or tunnel with a curved approach road. It is here that the latest methods and standards need to evolve. By testing the selected lighting products in the more complicated model a solution is found that uses the lowest amount of energy and equipment.

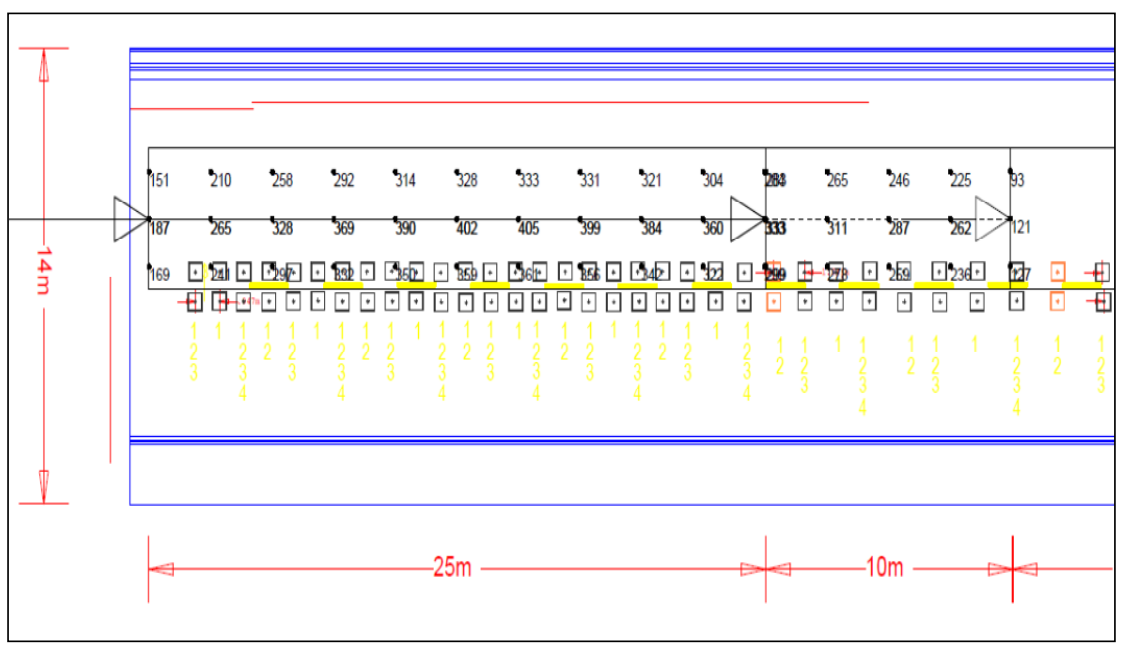

Figure 5: $\quad$ Example lighting layout of complex model plan view - supplier A.

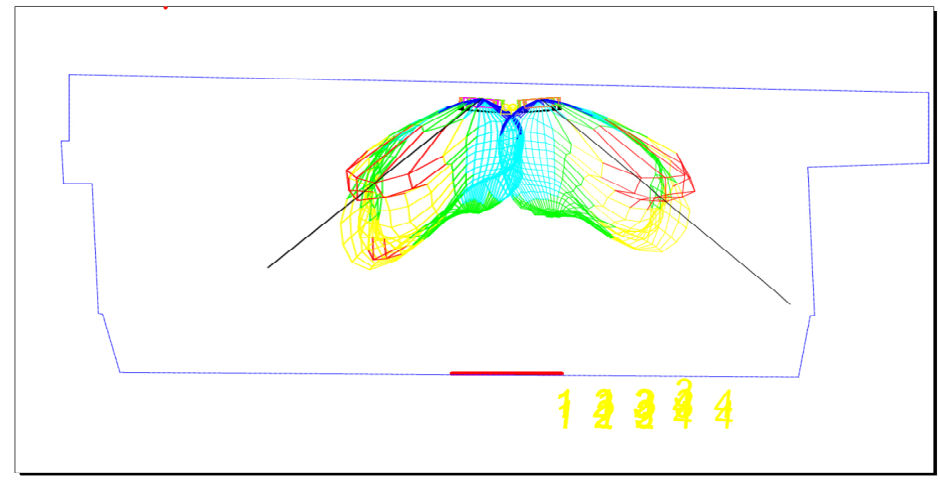

Figure 6: Cross section view - with photometric web turned on. Demonstrating the complex shape of the tunnel.

\section{A whole of life comparison}

The whole of life comparison spreadsheet compares the information from the first and second choices of light fittings. It may not be the cheapest light fitting that has the best whole of life cost calculation. The calculation also considers 
overall purchase price, with the added costs of lamp and parts replacement across a chosen life span (20 or 30 years)

With factors added for ease of installation, replacement parts costs and estimates of numbers required, the final whole of cost equation provided a choice mechanism for the operators, designers and constructors of the tunnel.

The following is extracted from the whole of cost spreadsheet. In the case study project there was the main real tunnel, plus a short underpass structure.

The background data for the costs includes installation labor estimates. The difference between light type $\mathrm{A}$ and $\mathrm{B}$ is apparent in the cost structure and installation loading. Refer Table 5 for variation in quantities and electrical loads.

Table 5: Whole of life cost summary.

\begin{tabular}{|l|c|c|c|c|c|}
\hline \multicolumn{2}{|l|}{ Price Comparison - Tunnel Lighting } & & & \\
\hline $\begin{array}{c}\text { Note - Running Costs Based on } \\
\text { 20c/kWh }\end{array}$ & $\begin{array}{c}\text { No of } \\
\text { Fittings }\end{array}$ & Total Value & Total kW & $\begin{array}{c}\text { Running Cost } \\
\text { PA }\end{array}$ & $\begin{array}{c}\text { Whole of } \\
\text { Life Cost }\end{array}$ \\
\hline SUPPLIER A Lighting - Long Tun & 360.0 & $\$ 460,370$ & 104.24 & $\$ 91,318$ & $\$ 2,743,314$ \\
\hline SUPPLIER A Lighting - Short Tun & 247.0 & $\$ 319,549$ & 83.18 & $\$ 72,866$ & $\$ 2,141,191$ \\
\hline SUPPLIER A Total & $\mathbf{6 0 7 . 0}$ & $\mathbf{\$ 7 7 9 , 9 1 9}$ & $\mathbf{1 8 7 . 4 2}$ & $\mathbf{\$ 1 6 4 , 1 8 3}$ & $\mathbf{\$ 4 , 8 8 4 , 5 0 5}$ \\
\hline & & & & & \\
\hline SUPPLIER B Lighting - LongTun & 365.0 & $\$ 414,758$ & 116.61 & $\$ 102,150$ & $\$ 2,968,517$ \\
\hline SUPPLIER B Lighting - Short Tun & 326.0 & $\$ 372,917$ & 108.54 & $\$ 95,079$ & $\$ 2,749,899$ \\
\hline SUPPLIER B Total & $\mathbf{6 9 1 . 0}$ & $\mathbf{\$ 7 8 7 , 6 7 5}$ & $\mathbf{2 2 5 . 1 5}$ & $\mathbf{\$ 1 9 7 , 2 3 0}$ & $\mathbf{\$ 5 , 7 1 8 , 4 1 7}$ \\
\hline
\end{tabular}

\section{Creating an accurate curve sided model}

To create a realistic 3D lighting model of a tunnel is ideally enabled with a 3D CAD model with surfaces making up the detail. These models are often available from the tunnel designing team, and can be imported into a Radiosity lighting program (Lighting Analysts [2]). There are inherent difficulties in this and often the $3 \mathrm{D}$ CAD model is better as a tool to assess all the variations in the tunnel geometry.

A 3D virtual model of the Logan tunnel was produced using the actual shape of the tunnel interior, with the curved walls and varying widths. Using the lighting solution selected in the process described above, the chosen lighting system was applied to the curving model.

Of course, as stated above, roadway luminance calculations are not possible in a curving model, or in a model with a curved approach road. To overcome this difficulty it was decided to use a metric common to all models - Illuminance on the carriageway. By switching on Illuminance calculation on the complex straight sided model, a basis for compliance is given. The assumption being that the relationship between a complying luminance calculation and the incident light on the carriageway can be considered a test. 


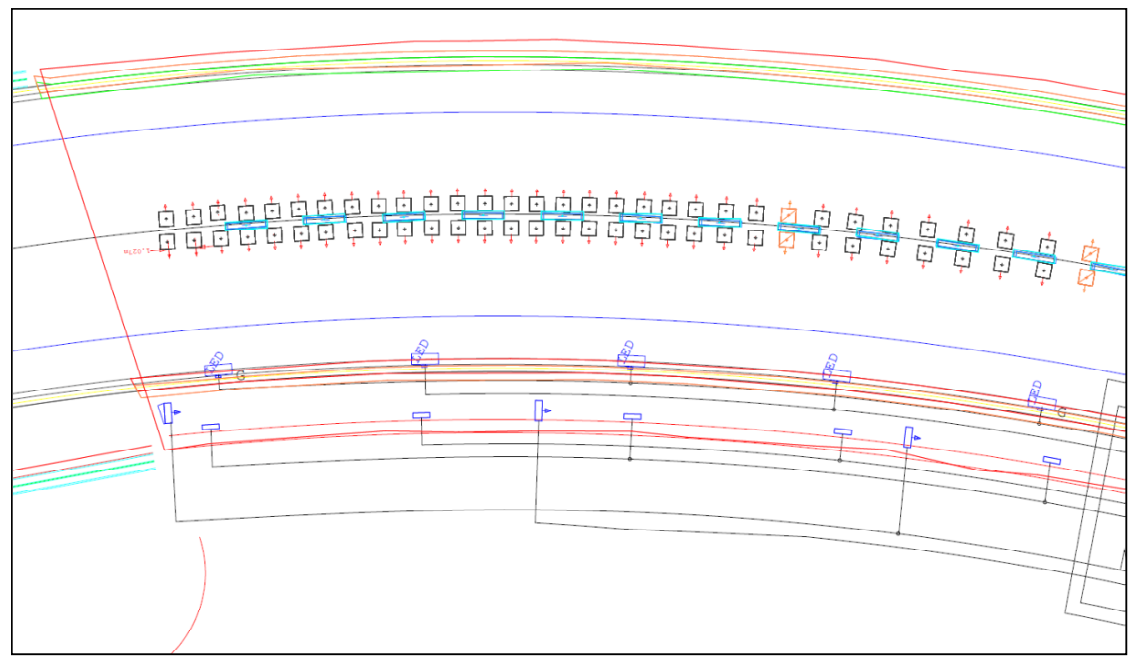

Figure 7: Example layout of a curved 3D model - as installed lighting layout.

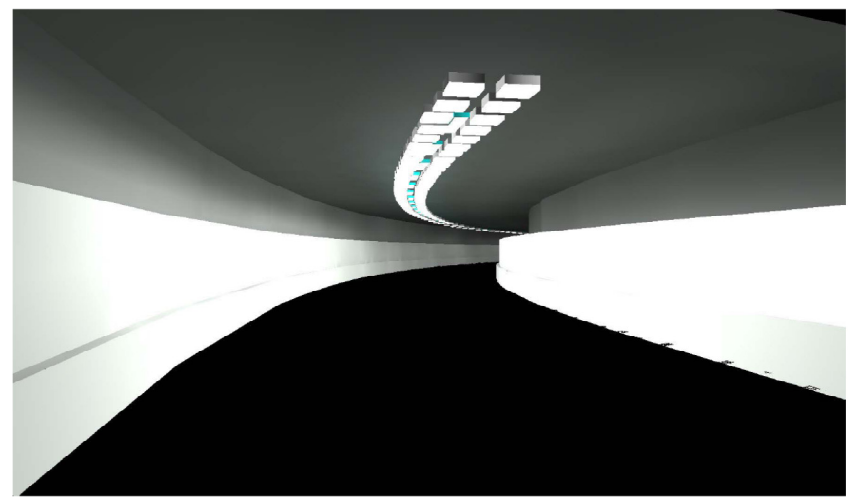

Figure 8: Cross section -rendered view - with photometric web turned on.

The comparison of the accepted complex model with a more realistic 3D virtual tunnel provides information about the application of the design process to reality. The differences between a simple design model, a complex design model and an assessment in a 3D virtual model can be used for improving the understanding of the tunnel lighting process.

\section{Comparing the results}

The Illuminance calculations for the complex straight model which was used to generate the construction drawing set is compared to the Illuminance calculation for the virtual 3D curved model. The difference between these two sets of results can be characterized as the Translation Factor (TF). 
Table 6: Calculation summary for complex straight model.

\begin{tabular}{|l|l|l|r|r|r|r|r|}
\hline Calculation Summary & & & \multicolumn{4}{|c|}{} & \\
Label & Calc Type & Units & Avg & Max & Min & Min/Av§ Min/Max \\
\hline CalcPts & Illuminance & Lux & 1066 & 3531 & 56 & 0.05 & 0.02 \\
\hline emergency lighting & Illuminance & Lux & 1115 & 3556 & 170 & 0.15 & 0.05 \\
\hline
\end{tabular}

Table 7: $\quad$ Calculation summary for curved model.

\begin{tabular}{|c|c|c|c|c|c|c|}
\hline \multicolumn{7}{|c|}{ Calculation Summary } \\
\hline Label & CalcType & Units & Avg & Max & Min & $\operatorname{Min} / \operatorname{Av} \grave{\operatorname{Min}} / \operatorname{Max}$ \\
\hline c-way & Illuminance & Lux & 989.7 & 6860 & 148 & $\begin{array}{ll}0.15 & 0.02 \\
\end{array}$ \\
\hline
\end{tabular}

The TF represents all the un-measured elements in the creation of the tunnel lighting design as a rectangular form when compared to the curved model. The $\mathrm{TF}$ is a test of the established design process. If the factor is high, then the design was not rigorous enough, and a low factor displays accuracy in design. Until the software companies develop different ways of calculating luminance from driver's position, or until the standards are changed to adopt other parameters that can be measured on curved carriageways and in curved tunnels, then I propose that this factor be used in all tunnel design to establish the degree of accuracy. Not a design factor like that used in simple models, the TF is based upon accuracy of design, rather than compensation for lack of design.

If the factor is greater than (say) $7.5 \%$, then it should warrant a design review and a modeling rethink. Perhaps an acceptable TF might be $5 \%$ or less.

The case history example has a factor of $7 \%$, which could be considered a significant result and warrants a check of the design prior to installation.

\section{Conclusion}

Careful design modeling provides the opportunity to improve design accuracy and create a design that is closer to the installation. This also reduces whole of life cost based upon the decisions that can be made using the information revealed during the process.

\section{References}

[1] Rayforge Services (Tulip Software), 1 Coventry Place, Pymble, NSW 2073, Australia.

[2] Lighting Analysts, Inc. (AGi32 software), 10440 Bradford Road, Unit A Littleton, Colorado 80127, U.S.A.

[3] Dial gmbh (Dialux software) GustavAdolf Strasse 4 d 58507 Ludenscheid. 